\title{
CORRIGENDUM
}

\section{Structure and function of the Rad9-binding region of the DNA-damage checkpoint adaptor TopBP1}

\section{Mathieu Rappas, Antony W. Oliver and Laurence H. Pearl}

Nucleic Acids Res. 2011; 39, 313-324. doi: 10.1093/nar/gkq743

The authors would like to apologize for the incorrect labeling of Figure 5, with respect to the phosphopeptide-binding characteristics of BRCT3 in human TopBP1.

The figure and its associated legend have been corrected - indicating that BRCT3 is predicted to be a non-phosphobinding singleton-which are now consistent with both the text of the manuscript and the information presented in Table 2.
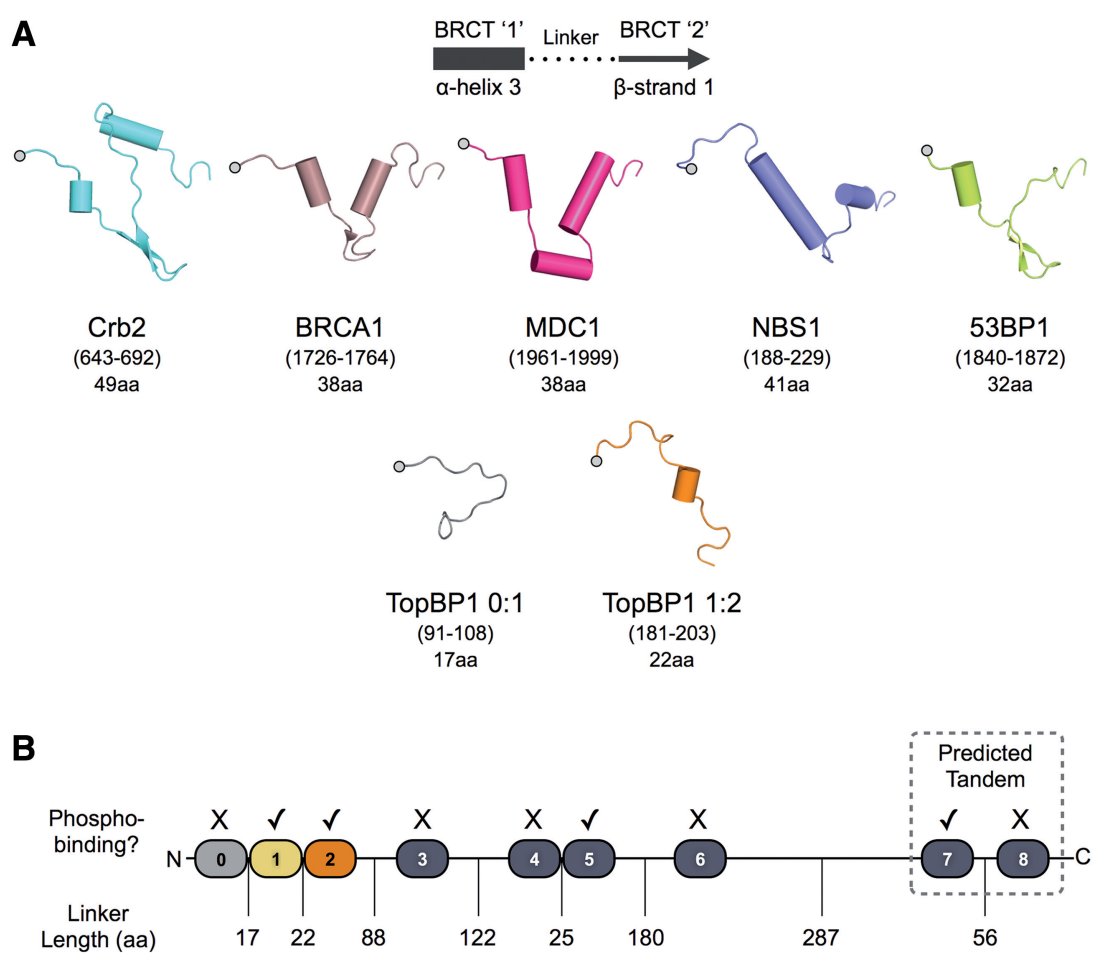

Figure 5. BRCT-domain classes in TopBP1 and other BRCT domain proteins. (A) Array of the linkers connecting consecutive BRCT domains in structurally characterized tandem BRCT proteins. The linker segments in the triple-BRCT structure of TopBP1 (1-290) are substantially shorter, resulting in the novel non-canonical domain arrangement. (B) Assignment of BRCT-domain classes in TopBP1. Domains 1, 2,5 and 7 show the characteristics of phosphopeptide binding, but only BRCT7:8 resembles the canonical tandem pair arrangement found in checkpoint mediators, such as Crb2, BRCA1 and so forth.

This correction does not influence the validity of the results and the conclusions of this article.

(C) The Author(s) 2013. Published by Oxford University Press.

This is an Open Access article distributed under the terms of the Creative Commons Attribution Non-Commercial License (http://creativecommons.org/licenses/ by-nc/3.0/), which permits unrestricted non-commercial use, distribution, and reproduction in any medium, provided the original work is properly cited. 